\title{
TIMBULAN SAMPAH ANORGANIK DI BEBERAPA RUANG PUBLIK DI KOTA TENTENA
}

\author{
Daily Amount of Inorganic Wastes in Several Public Spaces at \\ Tentena Town
}

\author{
Nurfhin IIma Bunga \\ e-mail : nbunga89@gmail.com \\ Fakultas Pertanian Universitas Kristen Tentena
}

\begin{abstract}
ABSTRAK
Penelitian ini bertujuan untuk : (1) Mengidentifikasi komposisi jenis sampah yang ada di beberapa ruang publik yang ada di Kota Tentena, (2) Mengetahui timbulan sampah yang ada di beberapa ruang publik yang ada di Kota Tentena. Metode yang digunakan dalam penelitian ini adalah survey dan wawancara yang dilakukan untuk meninjau fasilitas pengelolaan sampah. Komposisi jenis sampah dan timbulan sampah dilakukan dengan melakukan perhitungan jumlah sampah $(\mathrm{kg} / \mathrm{hari})$ dibagi dengan jumlah hari sampling. Hasil penelitian menunjukan komposisi jenis sampah (\% berat) terbanyak adalah plastik $(57,51 \%)$, kertas $(32,22 \%)$, kaleng $(6,22 \%)$ dan jenis sampah lain $(4,05 \%)$.. Timbulan sampah terbesar terdapat pada lokasi Kampus Universitas Kristen Tentena dengan jumlah timbulan $6,52 \mathrm{~kg} / \mathrm{hari}$. Untuk keseluruhan jumlah timbulan sampah adalah 13,34 kg/hari.
\end{abstract}

Kata kunci : Kota Tentena, Komposisi Sampah, Timbulan

\section{PENDAHULUAN}

Tentena merupakan ibukota

Kecamatan Pamona Puselemba yang terdiri dari beberapa kelurahan yakni Kelurahan Tentena, Kelurahan Sangele dan Keluruhan Pamona dengan luas masing-masing $27,77 \mathrm{~km}^{2}, 13,82 \mathrm{~km}^{2}$, dan $40,90 \mathrm{~km}^{2}$. Jumlah penduduk dari masingmasing kelurahan yaitu 1.724 jiwa, 4.383 jiwa dan 5440 jiwa (Badan Pusat Statistik, 2015). Letak Kota Tentena yang strategis sebagai tujuan wisata menyebabkan kota ini banyak dikunjungi oleh wisatawan lokal maupun wisatawan mancanegara. Sebagai salah satu kota tujuan wisata yang sudah mulai berkembang, aktivitas dan kebutuhan penduduk dibeberapa ruang publik juga semakin bertambah.

Salah satu masalah yang ditimbulkan adalah meningkatnya produksi sampah. World Health Organization (WHO) sampah adalah sesuatu yang tidak digunakan, tidak dipakai, tidak disenangi atau sesuatu yang dibuang yang berasal dari kegiatan manusia dan tidak terjadi dengan sendirinya (Chandra, 2006). Menurut Kodoatie (2005), sampah adalah limbah atau buangan yang bersifat padat, setengah padat yang merupakan hasil sampingan dari kegiataan perkotaan atau siklus kehidupan manusia, hewan maupun tumbuh-tumbuhan. Sumber limbah padat (sampah) perkotaan berasal dari permukiman, pasar, kawasan perkotaan dan perdagangan, kawasan perkantoran dan sarana umum, kawasan industri, peternakan hewan, dan fasilitas lainnya. Sampah organik dan anorganik merupakan penyebab dari pencemaran daratan yang diakibatkan oleh ulah dan aktivitas manusia (Wardhana, 2004). Pencemaran daratan merupakan masalah yang perlu mendapat perhatian yang seksama dan sungguh-sungguh agar daratan tetap dapat memberikan daya dukung alamnya bagi kehidupan manusia.

Pengelolaan sampah di Kota Tentena telah dikelola oleh Badan Lingkungan Hidup dan Dinas Perumahan dan Kebersihan Kota. Namun, pengelolaan sampah di Kota Tentena belum cukup memadai, hal ini dapat dibuktikan dengan tempat pembuangan akhir (TPA) sampah yang belum dikelola dengan baik dimana sampah hanya ditumpuk dan dibakar. Kota Tentena belum memiliki data timbulan sampah. Untuk itu, perlu dilakukan penelitian mengenai timbulan sampah di Kota Tentena. 


\section{METODE PENELITIAN \\ Tempat dan Waktu Pelaksanaan}

Tempat pelaksanaan penelitian yaitu beberapa ruang publik yang ada di Kota Tentena yakni Terminal, Taman Kota Tentena, Pasar Sentral dan Kampus Universitas Kristen Tentena. Penelitian dilaksanakan pada bulan Februari - Maret 2016.

\section{Prosedur Penelitian : Studi Literatur}

Studi literatur bertujuan untuk memperdalam dan mempertajam teori dasar yang berhubungan dengan timbulan dan komposisi sampah yang diperoleh dari buku-buku referensi, jurnal dan penelitian sebelumnya.

\section{Pengumpulan Data Sekunder}

Data sekunder yang diperlukan pada penelitian ini antara lain gambaran umum Kota Tentena seperti jumlah penduduk, luas daerah, peta topografi, dan mengidentifikasi jumlah ruang publik yang ada di Kota Tentena.

\section{Pengumpulan Data Primer}

Data primer yang dikumpulkan adalah data jenis sampah, data jenis sampah dalam penelitian ini dibatasi Tabel 1. Jenis Sampah

\begin{tabular}{ll}
\hline No. & Jenis Sampah \\
\hline 1 & Plastik \\
\hline 2 & Kertas \\
\hline 3 & Kaleng \\
\hline 4 & DII \\
\hline
\end{tabular}

Sampah yang sebagian besar ditemukan ialah sampah plastik, kertas, hanya untuk sampah anorganik. Jumlah sampah dalam satuan berat $(\mathrm{kg})$ setiap hari selama hari pengamatan, jenis fasilitas pengelolaan sampah

\section{Pengolahan dan Analisis Data}

Data yang diperoleh dilapangan dianalisis dengan menggunakan rumus :

Timbulan Sampah :

$$
=\frac{\text { Jumlah Sampah }}{\text { Jumlah Hari Sampling }}
$$

- Timbulan sampah yaitu jumlah sampah per hari dalam $\mathrm{kg} / \mathrm{hari}$ atau $\mathrm{m}^{3} /$ hari.

- Jumlah sampah yaitu jumlah sampah yang terhitung dalam $\mathrm{kg} / \mathrm{m}^{3}$ yang terhitung saat dilakukan sampling

\section{HASIL DAN PEMBAHASAN}

\section{Identifikasi Jenis Sampah}

Berdasarkan hasil identifikasi sampah, jenis sampah yang ditemukan di beberapa ruang publik di Kota Tentena adalah sebagai berikut :

\section{Jumlah Berdasarkan Jenis \\ Sampah Plastik}

Jumlah sampah plastik yang ditemukan

adalah sebagai berikut

kaleng dan jenis sampah lain berupa percahan kain, kaca dan lain-lain.

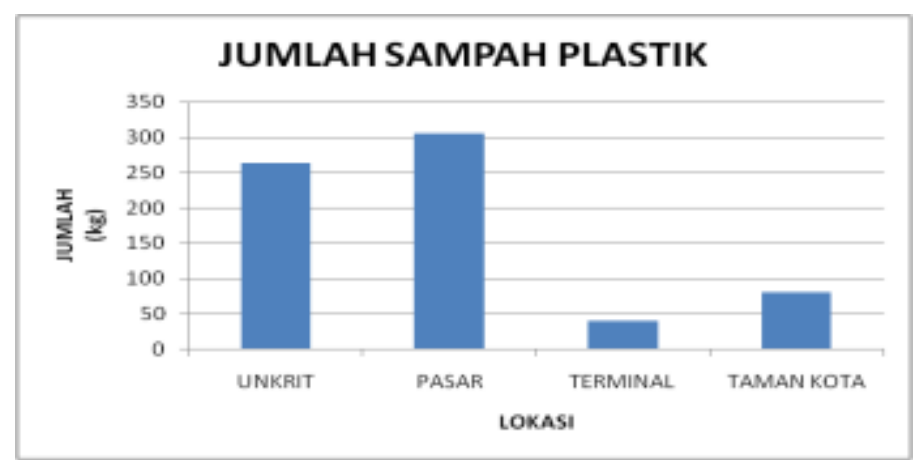

Gambar 1. Jumlah Sampah Plastik 
Sampah plastik terbanyak diperoleh di areal pasar, kemudian diikuti oleh kampus

\section{Sampah Kertas}

Jumlah sampah kaleng yang ditemukan adalah sebagai berikut.
Universitas Kristen Tentena, Terminal dan Taman Kota Tentena.

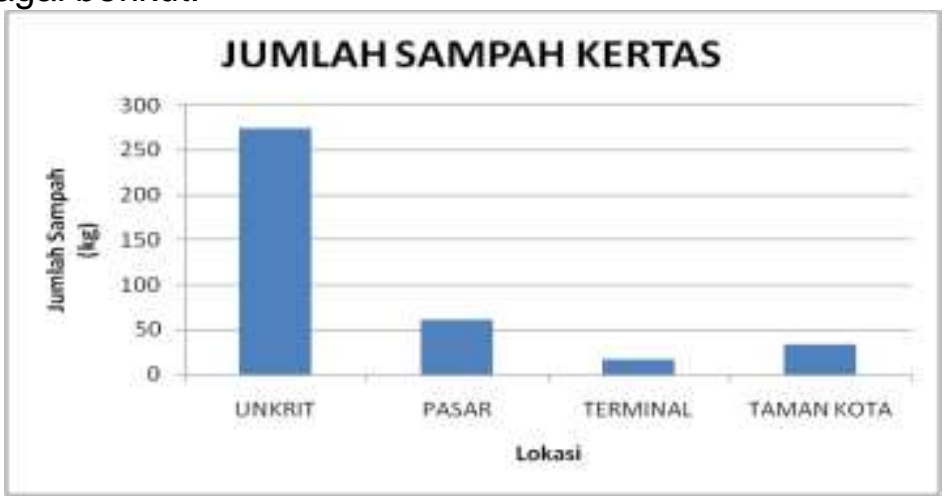

Gambar 2. Jumlah Sampah Kertas

Untuk sampah kertas, jumlah terbanyak diperoleh di Kampus Universitas Kristen Tentena, kemudian

\section{Sampah Kaleng}

Jumlah sampah kaleng yang ditemukan adalah sebagai berikut. diikuti areal Pasar, Terminal dan Taman Kota Tentena.

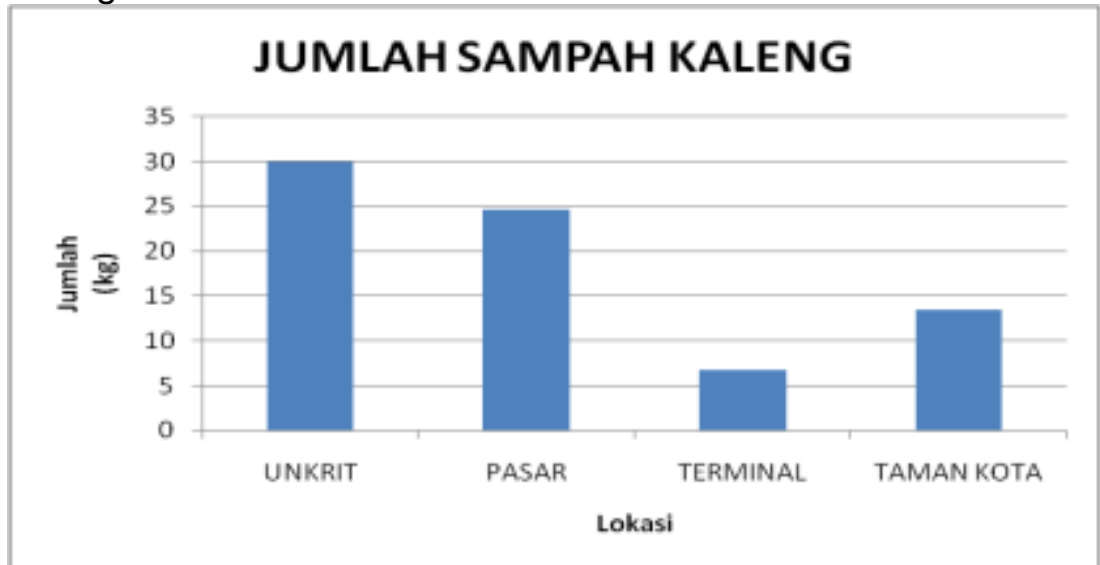

Gambar 3. Jumlah Sampah Kaleng

\section{Sampah Jenis Lain}

Jenis sampah lain yang ditemukan adalah kain perca, kaca dll. Karena jumlahnya relatif sedikit, maka sampah tersebut disatukan kemudian dijumlah berat totalnya. Jumlah sampah tersebut yaitu sebagai berikut. 


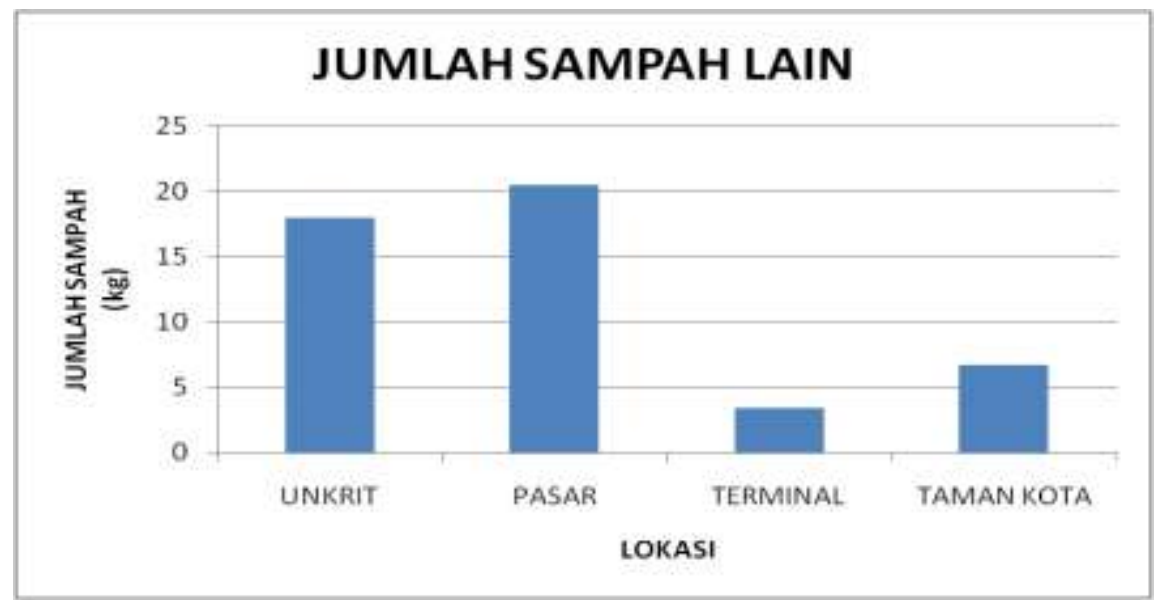

Gambar 4. Jumlah Sampah Jenis Lain

Jumlah Sampah Berdasarkan Lokasi

Berdasarkan lokasi observasi, jumlah sampah yang ditemukan adalah sebagai berikut :

Tabel 2. Jumlah Sampah Anorganik Berdasarkan Lokasi

\begin{tabular}{rcccccc}
\hline \multirow{2}{*}{$\begin{array}{c}\text { Jenis } \\
\text { Sampah }\end{array}$} & \begin{tabular}{c} 
JAMPUS \\
\cline { 2 - 6 }
\end{tabular} & $\begin{array}{c}\text { KASAR } \\
\text { UIWARIT } \\
\text { LEMBA }\end{array}$ & TERMINAL & $\begin{array}{c}\text { TAMAN } \\
\text { KOTA }\end{array}$ & JUMLAH \\
\hline Plastik & 264.06 & 305.64 & 40.32 & 80.28 & 690.3 \\
\hline Kertas & 274.77 & 61.65 & 16.8 & 33.45 & 386.67 \\
\hline Kaleng & 29.94 & 24.66 & 6.72 & 13.38 & 74.7 \\
\hline DII & 18 & 20.55 & 3.36 & 6.69 & 48.6 \\
\hline JUMLAH & $\mathbf{5 8 6 . 7 7}$ & $\mathbf{4 1 2 . 5}$ & $\mathbf{6 7 . 2}$ & $\mathbf{1 3 3 . 8}$ & $\mathbf{1 2 0 0 . 2 7}$ \\
\hline
\end{tabular}

Jumlah sampah terbanyak dapat ditemui pada lokasi Kampus Universitas Kristen Tentena dengan jumlah sampah $586,77 \mathrm{~kg}$. Faktor yang mempengaruhi jumlah sampah di lokasi tersebut lebih banyak dibandingkan dengan lokasi yang lain adalah sampah tersebut merupakan sampah yang sudah bertumpuk selama beberapa waktu serta dibiarkan begitu saja tanpa ada pengelolaan. Sedangkan pada lokasi lain, jumlah sampah relatif sedikit karena sampah tersebut tidak ditumpuk dan dikelola oleh pihak pengelola. Seperti pada pasar setiap harinya sampah yang ada dibersihkan oleh petugas kebersihan dan diangkut oleh truk sampah. Sedangkan di areal Taman Kota, sampah yang berserakan dibersihkan oleh pihak pengelola Taman Kota, yang dilaksanakan setiap hari pukul 06.00 pagi. Pada areal Terminal jumlah sampah paling sedikit, hal ini dipengaruhi oleh faktor belum difungsikannya terminal sehingga kurangnya aktivitas penduduk di Terminal.

Fasilitas Tempat Sampah dan Pengelolaannya

Fasilitas tempat sampah yang ada tersedia di beberapa ruang publik tersebut sudah cukup memadai tempat sampah tersebut berupa tong sampah, bak sampah serta truk pengangkut sampah. Tersedianya fasilitas tempat sampah tersebut seharusnya sudah dapat mengurangi berserakannya sampah di ruang-ruang public tersebut. Berdasarkan hasil observasi dan wawancara yang dilakukan terhadap pengelola tempat, dapat disimpulkan bahwa masih kurangnya kesadaran masyarakat terhadap kebersihan dan kesadaran untuk membuang sampah pada tempatnya

\section{Komposisi Jenis Sampah}

Menurut Achmadi (2004), secara umum komposisi dari sampah di setiap kota bahkan negara hampir sama. 
Komposisi jenis sampah dapat dilihat pada Tabel 1. Komposisi atau susunan bahanbahan sampah merupakan hal yang perlu diketahui. Hal ini penting kegunaannya untuk pemilahan sampah serta pemilihan alat atau sarana yang diperlukan untuk pengelolaan sampah.

Tabel 3. Persentase Komposisi Sampah

\begin{tabular}{|c|c|c|}
\hline No. & Jenis Sampah & Persentase \\
\hline 1 & Kertas & 35 \\
\hline 2 & Logam & 7 \\
\hline 3 & Gelas & 5 \\
\hline 4 & Sampah halaman dan dapur & 37 \\
\hline 5 & Kayu & 3 \\
\hline 6 & Plastik & 7 \\
\hline 7 & Lain-lain & 6 \\
\hline
\end{tabular}

Komposisi sampah yang diperoleh di beberapa ruang publik Kota Tentena dapat dilihat pada Gambar 1 sebagai berikut :

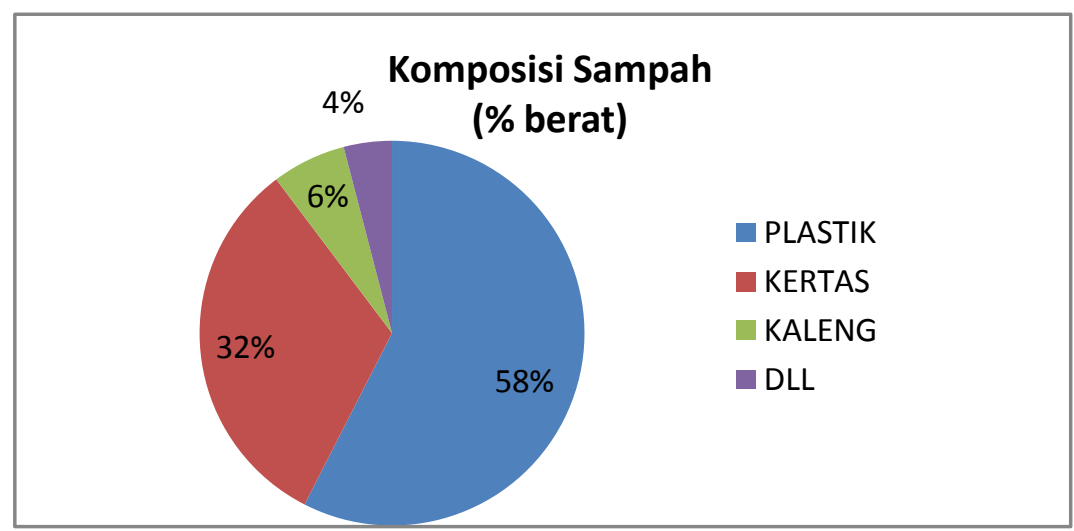

Gambar 1. Persentase Komposisi Sampah di Beberapa Ruang Publik di Kota Tentena

Sampah terbanyak yang dihasilkan adalah plastik dengan jumlah (\% berat) 58 $\%$, kemudian diikuti sampah kertas $32 \%$, kaleng $6 \%$ dan jenis sampah lain $4 \%$.

\section{Timbulan Sampah}

Pengukuran timbulan sampah dilakukan dengan mengumpulkan semua jenis sampah yang berserakan di lokasi pengamatan. Sampah tersebut dipilah berdasarkan jenisnya dan dimasukan kedalam trash bag kemudian ditimbang. Hasil dari pengukuran timbulan sampah tersebut dapat dilihat pada Tabel 4. 
Tabel 4. Hasil Pengukuran Timbulan Sampah

\begin{tabular}{llrrrrr}
\hline \multirow{2}{*}{ No. } & Jenis & Sampah & \begin{tabular}{c} 
JUMLAH TIMBULAN (kg/hari) \\
\cline { 3 - 7 }
\end{tabular} & $\begin{array}{c}\text { KAMPUS } \\
\text { UNKRIT }\end{array}$ & $\begin{array}{l}\text { PASAR } \\
\text { SIWAGI } \\
\text { LEMBA }\end{array}$ & \multicolumn{3}{c}{ TERMINAL } & $\begin{array}{c}\text { TAMAN } \\
\text { KOTA }\end{array}$ & JUMLAH \\
\hline 1 & Plastik & 264.06 & 305.64 & 40.32 & 80.28 & 690.30 \\
\hline 2 & Kertas & 274.77 & 61.65 & 16.80 & 33.45 & 386.67 \\
\hline 3 & Kaleng & 29.94 & 24.66 & 6.72 & 13.38 & 74.70 \\
\hline 4 & DII & 18 & 20.55 & 3.36 & 6.69 & 48.60 \\
\hline & JUMLAH & 586.77 & 412.50 & 67.20 & 133.80 & 1200.27 \\
\hline & TIMBULAN & $\mathbf{6 . 5 2}$ & $\mathbf{4 . 5 8}$ & $\mathbf{0 . 7 5}$ & $\mathbf{1 . 4 9}$ & $\mathbf{1 3 . 3 4}$ \\
\hline
\end{tabular}

Dari Tabel 4 dapat dilihat bahwa jumlah timbulan sampah berbeda untuk setiap lokasi. Jumlah timbulan sampah terbesar terdapat pada lokasi Kampus Universitas Kristen Tentena yaitu 6,52 $\mathrm{kg} /$ hari, selanjutnya Pasar Siwagi Lemba 4,58 kg/hari, Terminal $0,75 \mathrm{~kg} /$ hari dan Taman Kota 1,49 kg/hari. Secara keseluruhan timbulan sampah yang dihasilkan adalah 13,34 kg/hari.

\section{KESIMPULAN}

Jenis sampah anorganik yang banyak dihasilkan di beberapa ruang publik di Kota Tentena adalah jenis plastik dengan persentase $58 \%$. Timbulan sampah terbesar terdapat pada lokasi Kampus Universitas Kristen Tentena dengan jumlah timbulan $6,52 \mathrm{~kg} / \mathrm{hari}$. Untuk keseluruhan jumlah timbulan sampah adalah 13,34 kg/hari.

\section{UCAPAN TERIMA KASIH}

Ucapan terima kasih disampaikan kepada pihak yang telah membantu peneliti dalam melakukan observasi antara lain pihak pengelola tempat observasi, mahasiswa yang mengampuh mata kuliah Pengantar Kajian Lingkungan Hidup khususnya mahasiswa Fakultas Pertanian dan Fakultas Ekonomi.

\section{DAFTAR PUSTAKA}

Achmadi, Rukaesih. 2004. Kimia Lingkungan. Penerbit Andi, Jakarta

Chandra, Budiman. 2006. Pengantar Kesehatan Lingkungan. EGC. Jakarta

Kodoatie, R.J, dan Roestam Sjarief, Ph.D, 2008. Pengelolaan Sumber Daya Air Terpadu Edisi Revisi. Yogyakarta : Penerbit Andi.

Badan Pusat Statistik Kabupaten Poso. 2015.

Badan Standardisasi Nasional. 1995. SNI 19-3964-1995: Metode Pengambilan dan Pengukuran Contoh Timbulan dan Komposisi Sampah Perkotaan.

Wardhana, W. A. 2004. Dampak Pencemaran Lingkungan. Penerbit Andi, Yogyakarta. 